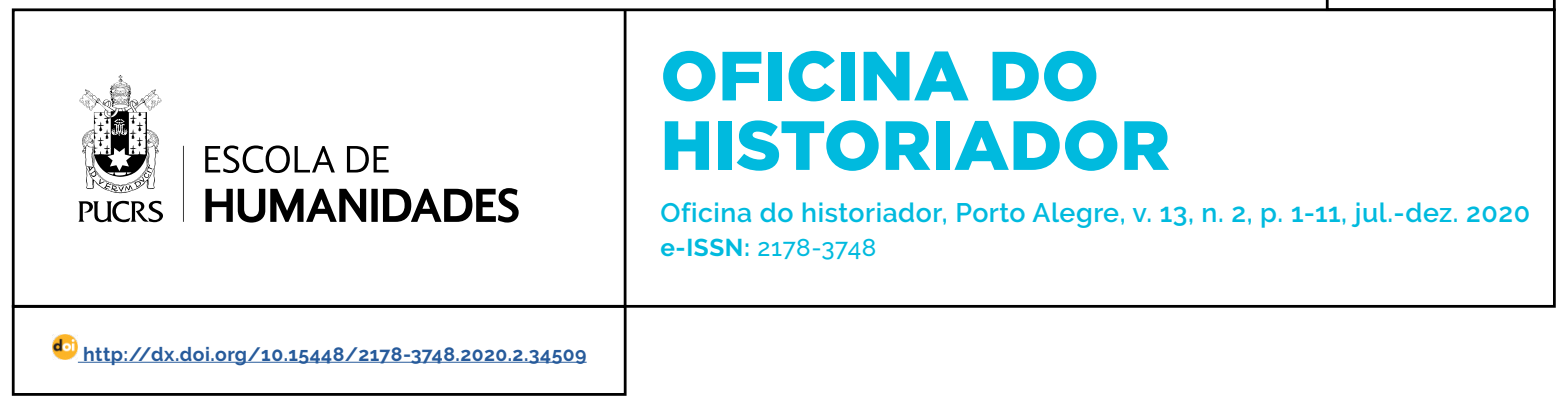

SEÇÃO: ARTIGOS

\title{
As três (3) transformações históricas e políticas da Renamo e a causa interna da Guerra Civil em Moçambique
}

\author{
The three (3) historical and political transformations of Renamo and the internal cause \\ of Civil War in Mozambique
}

\section{Celestino Taperero \\ Fernando ${ }^{1}$}

orcid.org/0000-0002-0019-1690

ctaperero@hotmail.com

Recebido em: 17 ago. 2019

Aprovado em: 29 jan. 2020.

Publicado em: 21 dez. 2020.

\section{(c) (i)}

Artigo está licenciado sob forma de uma licença Creative Commons Atribuicãa 4.0 Internacional.
Resumo: O presente artigo tem como objetivo detalhar as três transformações da Resistência Nacional Moçambicana (Renamo) como um movimento da guerrilha e adesão da população para o movimento da Guerrilha como forma de recuperar sua identidade. Também, explicar-se-á nesse artigo os periodos das transformações políticas e estratégicas da Renamo desde 1976 a 1992. Contudo, a Renamo é um movimento de guerrilha fundada em 1976 e começou as suas incursões armadas em 1977 na província de Manica e Sofala após a independência de Moçambique, com discurso virado na luta contra o marxismo-leninista que o país atravessava na época.

Palavras-chave: Renamo. Moçambique. Frelimo. Marxismo. Guerrilha.

Abstract: This article aims to explain the influence of internal conflicts on the emergence of Mozambican National Resistance (RNM) and the population's adhesion to the Guerrilla movement as a way to recover its identity. Also, this article will explain the periods of Renamo's political and strategic transformations from 1976 to 1992. However, the Renamo is a guerrilla movement founded in 1976 and began its armed incursions in 1977 in the province. de Manica and Sofala after the independence of Mozambique, with a discourse turned in the struggle against Marxist-Leninist that the country was going through at the time. Keywords: Renamo. Mozambique. Frelimo. Marxism. Guerrilla.

\section{Introdução}

Entre 1976 a 1992, historicamente, a jovem nação moçambicana é marcada por um ciclo de eventos sociopolíticos e econômicos muito relevantes para sua restruturação.

O movimento, que foi criado em 1976 com a designação de Mozambique National Resistance (MNR), mais tarde Resistência Nacional Moçambicana (Renamo), foi fundado por coligações entre pessoas de aproximadamente quatro países, Rodésia (Zimbabwé), Moçambique, Portugal (ex-colônia) e Brasil.

Os agentes secretos rodesianos, considerados principais mentores do projeto MNR, nos documentos está explicito que contaram com a colaboração dos imigrantes colonos portugueses na Rodésia do Sul. Os colonos espoliados, ressentidos e frustrados pelas suas riquezas nacionalizadas pelo governo de transição, e uma parte dos moçambicanos, que estavam também decepcionados com a forma como a independência estava sendo gerida pelo novo governo, uniram-se e formaram a guerrilha. 
Ao desenhar o projeto da insurgência para Moçambique, os rodesianos nunca cogitaram designar um moçambicano como o lider desse projeto. Mas por necessidade de aceitação social da guerrilha no meio social moçambicano, que dizia tudo ou nada, mas menos o homem branco, PINTO (1994, p. 23) sustenta que a estratégia usada pelos rodesianos foi colocar no comando do movimento o moçambicano e revoltoso André Matsangaissa, que hoje é considerado como o fundador da resistência. Isto é, todas as propagandas eram feitas por André Matsangaissa e outros moçambicanos. Mas importa referir que o André Matsangaissa foi ex-militar da Frente de libertação de Moçambique (Frelimo), que fugiu na prisão em Gorongosa para Rodésia em procura de ajuda para formar um movimento, o motivo da fuga foi devido à violência que estava instalada nos campos de reeducação em Moçambique.

Foucault (2010) afirma que a violência não precisa ser física, marcada no corpo, mas não deixa de ser uma violência psicológica, em que o próprio individuo com receio de ser punido ou excluido, se autovigia constantemente. associando a esse pensamento é importante dizer que a elite da Frelimo afirmava que não se tratava de uma violência nem exclusão apenas era uma forma de reestruturar uma sociedade

Para sustentar essa ideia Foucault no seu livro: o corpo utópico, as heterotopias. Argumenta que:

Segundo principio da ciência heterotopologica: no curso de sua história, toda sociedade pode perfeitamente diluir e fazer desaparecer uma heterotopia que constituirá outrora, ou então, organizar uma que não existisse ainda". Por exemplo, há cerca de vinte anos, a maioria dos paises da Europa tentou fazer desaparecer as casas de prostituição, com sucesso reduzido, como se sabe, pois, o telefone substituiu a velha casa de nossos avos por uma teia fina e bem mais sutil. Neste contexto podemos ver que os campos de reeducação em Moçambique pós-independência foram arquitetadas como um sendo lugar de repressão para todos considerados inimigos da nação e os improdutivos (FOUCAULT, 2013, p. 22).

A Operação Produção insere-se bem na perspectiva ideológica global do partido-Estado implementado pela Frelimo e acabar com as ideologias obscuras do passado. Depois da proclamação da independência, o projeto (ideia) da construção do Homem Novo passou a estar diretamente conectada ao projeto de Estado Nação rumo ao desenvolvimento, e a ideia da revolução encontrou terra fértil. Para isso, não foi envolvida (afetada) apenas a população, mas também os guerrilheiros da Frelimo, que eram presos em campo de educação. Dentro desse raciocínio histórico surge uma questão: quem se aproveitou da fúria do outro?

A resposta sobre essa questão pode até não ser cabal, mas, se olharmos nos acontecimentos subsequentes da guerra, verificaremos que são moçambicanos que necessitavam de apoio para implementar o seu projeto contra o marxismoleninista, a ditadura militar do sistema de partido único em que o país estava mergulhado,

Como pode se ler no livro de Geffray (1991), no qual ele cita Ken Flower, um dos principais membros rodesianos, fundador do MNR, sustentou que a maior parte dos observadores acreditava que, com o fim do que originalmente tinha levado à sua criação, o MNR iria desaparecer por si próprio.

Tal não foi o caso, e Ken Flower reconhece que nessa altura os seus serviços secretos tinham perdido o controle da dinâmica e do destino do grupo militar. cuja formação tinham apoiado e orientado, interroga-se se não teria criado um monstro (GEFFRAY, 1991. p. 11).

Isso revela que havia um jogo duplo, ou seja, os moçambicanos fingiam serem usados, mas na realidade eles mesmos é que estavam muito interessados pela guerra para alimentar os seus intentos.

Esse viés histórico nos remete a uma importante razão de abandonarmos o discurso linear de que as guerras africanas são instrumentalizadas pelas potências internacionais, e passarmos a olhar para o fato de que alguns africanos têm desejos de fazer a guerra por diversos motivos (ganância de poder, saque dos recursos naturais existentes para enriquecimento individual) e recorrem a apoiantes externos porque é neles onde encontram os interesses comuns sobre os países. 


\section{As transformações e evolução da Renamo em Moçambique}

Para compreendermos melhor a evolução da história política da Renamo é fundamental enquadrála cronologicamente em três períodos pelos quais sucederam suas transformações: 0 primeiro periodo vai se estender desde a sua criação, em 1976, a 1984, "período da assinatura do Acordo de Nkomati, ${ }^{2}$ conhecido como acordo de boa vizinhança entre Moçambique de Samora Machel e África do Sul de Piter Botha" (MSABAHA, 1987, p. 231).

Nesses primeiros sete anos a resistência foi essencialmente conhecida como um instrumento desestabilizador de Moçambique, e seus membros como bandidos armados. Nessa altura, tanto em Maputo como em outras cidades, os integrantes do movimento recebiam acrônimos de matsanga, bandidos, mudjibas, chimuendje, nomes que fomentavam o discurso de que a Renamo era formada por estrangeiros e usava os moçambicanos para devastar a economia e desenvolvimento humano do próprio país.

Neste sentido, é necessário estarmos ciente de que nenhuma narrativa é objetiva. Essa é a natureza da história de modo geral: que os espaços entre os fatos são preenchidos pelas suposições do historiador, usando as fontes que o convém. E, assim, reconhecida a necessária subjetividade desse texto, importa afirmamos que essa história é, por sua natureza, politicamente controversa. Isso mostra que neste artigo, não chegaremos com nitidez às conclusões morais e politicas definidas sobre os assuntos examinados, apenas iremos fazer uma ponte e criaremos a nossa tese.

Entre pesquisadores simpatizantes da Frelimo - aqueles que Geffray, Chain, Roesch, Cabrita e Pinto preferiram chamar de elites intelectuais de Maputo -, estão nomes como de Malyn Newitt, Edward Alpers, Ruth First, Allan Isaacman, Keith Middlemass, William Minter, A. K. Smith. Esses cientistas sociais e historiadores preferem ignorar os acontecimentos citados e unem-se ao afirmar que a Renamo, isto é, apontando, assim, os governos da minoria branca da Rodésia e da África do Sul como protagonistas, coadjuvados pelos imigrantes portugueses na Rodésia migrantes devido à independência de Moçambique.

Malyn Newit (1995) no seu livro, História de Moçambique, afirma que,

\begin{abstract}
aqueles que estavam mais envolvidos na oposição à FRELIMO fugiram para o estrangeiro levando consigo uma determinação de sabotagem do novo regime. O governo de lan Smith foi o primeiro a dar algum apoio aos moçambicanos dissidentes (NEWIT,1995, p. 442).
\end{abstract}

Esses suportam-se nas teses de Dias, na qual a Renamo é oriunda dos 8 homens que iremos mencionar nos parágrafos a seguir. Para Newit, "Jorge Jardim e o seu agente Orlando Cristina terão fugido com alguns processos da DGS e ajudado os Rodesianos a fundar a Renamo recrutando elementos das unidades militares e paramilitares negras que haviam combatido para os Portugueses" (NEWIT,1995, p. 442). Sob o controlo firme da organização de segurança rodesiana, "a Renamo desenvolveu-se primeiro como uma unidade militar e não como um movimento político nesse ano" (ALEXANDER, 1997, p. 8), isso quer dizer que o movimento não possuía uma ideologia claramente definida nem tinha projeto político difundido. Observa-se que a sua propaganda se estruturava em torno de uma oposição explícita às políticas da Frelimo - centrando-se na defesa das tradições e das autoridades tradicionais (GEFFRAY, 1991, p. 117119) com intuito de ter o apoio dos espíritos dos antepassados na sua guerra contra o partidoEstado (ROESCH, 1993).

Geffray (1991), que também não se distancia dessa elite apesar de ser moderado, elenca que no princípio, a Renamo atuava como uma guerrilha mercenária, mas aos poucos, poucos vai engrossando o seu exército, principalmente através de recrutamento forçado, mas também por adesão voluntária de jovens e de chefes tradicionais acompanhados pelos seus dependentes.

\footnotetext{
2 O Acordo de Nkomati foi assinado em 1984 entre o governo de Moçambique, liderado pelo então Marechal Samora Moisés Machel, presidente da República Popular de Moçambique, e pelo presidente da África do Sul, Pieter Willem Botha, para deixar de apoiar a Renamo (conhecido como acordo de boa vizinhança).
} 
Evidentemente, a Renamo nas suas primeiras excursões militares agia de forma trágica e ostentava caraterísticas de um movimento terrorista. E, nesse periodo, os caminhos de ferros, as escolas, os hospitais, as estradas, as pontes, a moagem, os autocarros, os saques nas lojas estatais, ou seja, tudo aquilo que pertencia à administração estatal, eram sabotados pelo movimento. Além disso, durante o período entre 1977 e 1980 a eliminação das aldeias comunais e as guias de marchas implementadas pela Frelimo eram seu ato principal e isso gerou muitas perdas e danos para a economia nacional.

Como podemos ver que foi nessa época que se registraram muitas baixas, com cerca de 1 milhão de mortes e cinco milhões deslocados para países vizinhos. Esses atos influenciaram na fundamentação da tese, na qual o movimento não era do interesse dos moçambicanos e não era da autoria dos moçambicanos, apesar de se saber que o seu comandante era moçambicano, André Matsangaisse, antigo comandante da Frelimo, ex-preso político de Sacudzi em Grongosa.

Como um adendo à essa ideia, é importante citar a entrevista de 1979 à rádio na "Voz da África Livre" do primeiro comandante da Renamo, Andrè Matsangaissa, dizendo: "Não estamos interessados em formular políticas... mais tarde teremos que trabalhar política, mas o primeiro é, o comunismo deve ir embora do nosso país" (ALEX, 1996, p. 77). Aqui a Renamo dá a entender que sua política estava numa única vertente.

O grande problema nesse periodo foi o movimento nunca ter apresentado um projeto político de como seria se conseguisse vencer a guerra. Mas, Dhlakama, sustenta que o movimento não queria ganhar o país pela guerra, porque a guerra era apenas um instrumento para pressionar a Frelimo a deixar o regime e depois eles iriam às eleições porque eles defendiam a democracia participativa e a liberdade de escolha, então seria contraditório orquestrar um golpe do Estado.

Mas a ideia de que o movimento estava a serviço de estrangeiros foi coeficiente da história do movimento nessa época, e extravasa no discurso cíclico de que era um movimento que tinha sido criado para matar, roubar e destruir toda a estrutura econômica, política e social de Moçambique (quando se abatia um guerrilheiro da Renamo era chamada toda população da aldeia comunal para ver e testemunhar que o insurgente não era realmente moçambicano, pela maneira de vestir e de se apresentar. Como se sabe que eles não tinham uma boa logística, tudo era de uma forma improvisada).

Como reconhecimento da causa interna desse movimento, os simpatizantes do marxismo e do partido único recorrem a uma analogia afirmando que para recrutamento dos seus efetivos a Renamo recorreu ao rapto de crianças (SEIBERT, 2003, p. 254-256). Geffray (1991, p. 72) declara que a Renamo era em parte um "exército de cativos", tendo vários autores referido a crescente desilusão sentida pelos agricultores que aderiram à sua causa à medida que a guerra progredia (GEFFRAY, 1991, p. 113-112; WILSON, 1991; ROESCH, 1993). A intenção desse autor é de reduzir a oposição moçambicana em apenas uma marionete dos estrangeiros.

Para cimentar essa ideia, Christian Geffray cita no seu livro: A Causa das Armas, Antropologia da Guerra Contemporânea em Moçambique, que as elites urbanas, os intelectuais nacionais e os estrangeiros difundem a imagem da Renamo que, "hoje treze anos que um bando de bandido assassinos sanguinários sem fé nem lei semeia o terror, a destruição e a morte em Moçambique", (GEFFRAY, 1991). Ou seja, para os alinhados ao regime o movimento armado nasce da nova conjuntura geopolítica regional, com a Rodésia da UDI desejosa de exercer represálias e de contrabalançar santuários e apoios para a ZANUPF no território moçambicano. Cerrando, assim, a possibilidade da insatisfação interna da população rural conservadora que Jaime Nogueira Pinto tem mencionado sempre no seu livro, Jogo dos Africanos. Geffray, cita essa versão para tentar dissipar esse equívoco sustentando que,

trata-se, no entanto, de uma visão insuficiente, e o seu carácter apaixonado esconde a complexidade e a profundidade dos processos sociais e políticos em curso nas zonas rurais de Moçambique impedindo a compreensão da sua natureza e alcance (GEFFRAY, 1991) 
O trabalho de William Minter entrevistando ex-combatentes também ajudou a demonstrare a compreendermos que a Renamo não era uma coleção frouxa de senhores da guerra. A Renamo, como projeto político dos moçambicanos, também tinha a capacidade de coordenar ou restringir ataques em todo o território, sem apoio dos estrangeiros no que tange recursos humanos e alimentícios. Na mesma linha, Vines, fundamenta que o que une a Renamo é o desejo de poder.

Vines (1992) argumenta que o núcleo de liderança da Renamo "é derivado de membros frustrados ou desiludidos da Frelimo que não conseguiram progredir o suficiente para as suas ambições dentro do partido" (VINES, 1992) Os argumentos de Vines (1992) anteriormente citados, nos levam a afirmar que é válida a tese na qual a Renamo tem sua gênese interna ${ }^{3}$ forte, que foi originada por descontento massiva da população rural devido a forma que o país estava sendo conduzido na pós-independência.

Com a implementação da política corporativista marxista leninista versado ao partido único (partido estado) a frelimo obrigou a população a abandonar todas suas práticas culturais religioso e maneira de vida e introduziu-se uma vigilância, com lema cada um deve saber quem é seu vizinho (Notícias, Maputo 3 de junho de 1982), esse lema sustentava implementação das guias de marchas aldeias comunais, campos de redução e produção, machamba e cooperativas. Essa prática suscitou muito descontentamento no seio da população rural.

Os pesquisadores mais moderados, ${ }^{4}$ como Christian Geffray, Jaime Nogueira Pinto, Sergio Chichava, Stephan Emerson e Celine defendem que a Renamo é resultado de um conjunto de razões, circunstâncias, vontades, sentimentos e ressentimentos que a população e uma parte da elite da Frelimo tinham sobre as políticas implementada depois da independência. Dando continuidade a mesma ideia dos cientistas políticos e historiadores acima citados, há necessidade de afirmarmos que nas mesmas circunstâncias nasce o movimento baseando-se e anexando-se no descontentamento de uma parte substancial da população rural, sobretudo, do centro e norte do país, em relação às politicas socialistas da Frelimo e ao seu modo de execução.

Com todas essas correntes surge a pergunta seguinte, qual é a verdade sobre a origem da Resistência Nacional Moçambicana?

Para respondermos essa questão, partimos por citar o livro intitulado: Memórias de um combatente: e a verdadeira sobre fundação da resistência nacional moçambicana, de autoria de João Ferro Dias na qual sentencia que a verdadeira fundação é raciocínio célere e unânime de oito homens que são: Pedro Rodrigues, João Ferro Dias, Povoa, Manuel Godinho, Rui Silva, Zeca Oliveira, Graciano e Silva. Dias, no mesmo livro, explica que ele foi elemento chave para estabelecer a ligação entre o projeto de Pedro Rodrigues, brasileiro, e o Estado rodesiano, onde ele era trabalhador dos serviços secretos. Para substanciar seu raciocino, Dias anexa no mesmo livro a primeira carta, datada de 20 de agosto de 1976, por ele redigidas para $\mathrm{P}$. Walls, homem poderoso dos serviços secreto do Ian Smith, na qual Dias escreve que; "não somos mercenários, mas sim homens de boa vontade e anti-comunista", (DIAS, 2008, p. 137). Pretendemos:

a) preservar a integridade política e territorial da Rodésia;

b) criar um clima de desentendimento e insegurança no seio da FRELIMO por forma a preparar, no mais curto prazo de tempo, as condições necessárias ao desencadeamento de ação tendentes a derrubar o regime vigente em Moçambique (DIAS, 2008, p. 136).

No livro, André Matsangaissa aparece citado como o grande aliado dos homens da $\mathrm{ClO}$ e representante da maioria negra descontente com autoritarismo comunista samoriano.

\footnotetext{
3 Com versão Vines, é importante dizer que valida a tese de que a Renamo tem um grande epicentro interno do que no exterior como o governo de Mapuo gostava de divulgar.

4 Partindo por essa concepção histórica dos moderados acima referenciado poder-se-ia chegar a uma conclusão de que a RENAMO como movimento anticomunista foi suportada e galvanizados pelos moçambicanos, muitos dos quais membros dissidentes da FRELIMO, que ficaram alarmados e descontentes com a tendência da FRELIMO para o marxismo e socialismo científico.
} 
No entanto, Dias afirma no mesmo texto que Pedro Rodrigues, de nacionalidade brasileira, era o chefe do movimento e André, de nacionalidade Moçambicana, o comandante adjunto. Afirma também que Dias não poderia sair do Salisbury, para cumprir o seu papel diplomático junto à unidade do partido Umtali (cidade mutare) que já estava se instalando em Manica. Rodrigues não consegue levar o movimento para a população devido à sua raça, que é branca, ai a única peça-chave seria André, que depois assumiu o movimento.

Estrategicamente, André Matsangaissa conhecia as matas de Manica por ser natural do distrito, isso, fez com que o ponto de entrada do movimento em Moçambique fosse a localidade fronteiriça de Mavita devido à sua potencialidade florestal e também ao seguimento das Cordilheiras de Chimanane.

Esse contato e as ações foram realizados no ano de 1976, mas para fechar devemos afirmar que, de início, o governo de Salisbury (Harare) não estava a par a ideia da criação de um movimento da guerrilha, mas, pelo aliciamento de João Ferro Dias $^{5}$ e Pedro Rodrigues, ${ }^{6}$ o governo da Rodésia, por via da $\mathrm{ClO}$ dirigida por Ken Flower, concordou com o apoio aos pequenos grupos de mercenário que esses pretendiam formar. Como afirma Dias no seu livro, "Pedro segure-me que contate a minha superior para que apoiasse uma incursão furtiva em terras" (DIAS, 2008, p. 135).

O fato curioso nesse design da fundação da Renamo reside na ocultação, por ambas as partes, do interesse entre André Matsangaissa e os estrangeiros na Rodésia do Sul. Como podemos ver, os estrangeiros branco não rodesianas (antigos colonos português de Moçambique) tinham a pretensão de "agitar as águas, mostrar à Frelimo que uma parte significativa do povo" (DIAS, 2008, p. 135) estava descontente pelo comunismo, por sua vez, os estrangeiros brancos rodesianos tinham a intenção de fazer uma operação contra rebeldes zimbabuanos pelas autoridades rodesianas e nacionalistas moçambicanas como forma de "conduzir uma campanha psicológica e clandestina contra o governo marxista moçambicano - e criar uma oposição suficientemente forte para desafiar a autoridade existente"7, enquanto que André Matsangaissa provando essa ganância de desestabilizar Moçambique por parte dos portugueses e dos rodesianos convencidos lança Matsangaissa para linha de frente. E o Matsangaissa vem que seu sonho de vingança contra o regime estava se tornar uma realidade e rapidamente lança o seu projeto de reestruturação das autoridades tradicionais e combate às políticas de operação produção, campos de reeducação e pena de morte no seio da população.

Na sua entrevista à Rádio África Livre Matsangaíssa sustentou que o objetivo da Renamo era da restauração do quadro político da Frelimo e recuperar as lideranças tradicionais que tinham sido marginalizados pela Frelimo. Para Matsangaíssa a guerra só poderia ter término quando a Frelimo renunciasse o comunismo e acabasse com sistema de partido único e com a perseguição dos opositores.

Matsangaissa faz esse pronunciamento para demostrar a comunidade internacional que a guerra que estava coordenando era de caráter ideológica, como forma de silenciar a ideia de que o seu movimento se tratava de bandidos armados a mando da Rodésia. É verdade e consensual que a essa altura faziam parte das fileiras da Renamo alguns antigos agentes da polícia, políticos portugueses e brasileiros, como também o regime racista da Rodésia do Sul e, mais tarde, da África do Sul, ou seja, dos paises considerados como patrocinadores principais do movimento e respectivos fundadores. Essa foi considerada como a primeira fase da Renamo como movimento armando.

A segunda fase inicia com a proclamação da independência da Rodésia, internacionalmente reconhecida, do Zimbabwe, em 18 de abril de 1980, "o MNR abandona com armas e bagagens

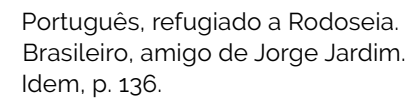


o território, que a partir de então se tinha tornado perigosamente hostil, para encontrar refúgio, como seria de esperar, junto do grande vizinho sul-africano" (GEFFRAY, 1991, p. 12). Funda as suas bases na totalidade em Moçambique e a guerra ganha outra dinâmica e ocupa todas as províncias do país, e o movimento ganha muita popularidade nas zonas hostis ao governo.

Aqui é importante ressaltar, junto à história da fundação da Renamo vêm as práticas coercivas do regime do homem novo, como a ausência da inclusão e incorporação da população para escolha do modelo político, a implementação da ditadura militar e sistema de partido único e centralizado, o hino nacional e a Constituição da República, tudo era a respeito do partido Frelimo.

Nesse caso a Frelimo não se preocupou em saber o que a população queria depois de alcançar a independência, porque na verdade a população moçambicana estava preocupada com a liberdade e não com a revolução que a Frelimo veio impor depois da independência. A revolução moçambicana floresceu com a implementação do sistema partido único, marxismo-leninista com as raizes nas aldeias comunais. Política que foi considerada uma estratégia para inserção do Estado nas zonas rurais, onde sobrevivia o conservadorismo tradicional cultural por parte da população. Mas para além dessa prática regimental, o partido não parou por aí, porque todas as estruturas de governo eram emanadas e chanceladas na sede do partido.

Nesse Estado (governo) revolucionário as indicações dos deputados e do Presidente da República eram feitas dentro do partido pelos membros do Comitê Central como órgão máximo da nação. Como podemos ler nos artigos $3 .^{\circ} \mathrm{e}$ 37. ${ }^{\circ}$ da Constituição da República de 1975:

A República Popular de Moçambique é orientada pela linha política definida pela Frelimo, que é a força dirigente do Estado e da Sociedade. A Frelimo traça a orientação política básica do Estado e dirige e supervisa a ação dos órgãos estatais a fim de assegurar a confor- midade da política do Estado com os interesses do povo. A Assembleia Popular é o órgão supremo do Estado na República Popular de Moçambique. A Assembleia Popular é o mais alto órgão legislativo da República Popular de Moçambique. Até ulterior definição da composição e dos critérios de eleição dos membros da Assembleia Popular. esta será constituida pelos seguintes membros: $1 .^{\circ}$ Os membros do Comité Central da Frelimo; $2^{\circ}$ Os membros do Comité Executivo da Frelimo; $3 .^{\circ}$ Os Ministros e Vice-Ministros do Governo da República Popular de Moçambique: $44^{\circ}$ Os governadores provinciais; $5^{\circ}$ Membros escolhidos pelo Comité Central da Frelimo de entre os quadros das Forças Populares de Libertação de Moçambique; 6. Dois representantes por provincia das organizações democráticas de massas, indicados pelo Comité Central da Frelimo; $7 .^{\circ}$ O Membros escolhidos pelo Comité Central de entre os quadros da Frelimo: 8. Um máximo de dez cidadãos idóneos escolhidos pelo Comité Central da Frelimo (MOÇAMBIQUE, 1975).

A revolução implementada pela Frelimo foi vista como com trafato daquilo que o povo estava lutando para ser, ealguns preferiram chamar de uma crueldade e traição às causas da independência. De acordo com Pinto (1994, p. 23), essa:

Crueldade julgado por uma parte significativa da população praticada pela Frelimo durante o período inicial da independência foi para além da criação de campos de reeducação, fuzilamento dos opositores da ideia de socialismo, abandono compulsivo das tradições e idiomas moçambicanos e da religião, falta de consideração pelo regionalismo, abolição dos lideres tradicionais (PINTO,1994, p. 23).

O governo formado apenas por homens do sul de Moçambique e partidarização das instituições do Estado são fatores principais que influenciaram o descontentamento no seio da população moçambicana depois da independência ${ }^{8}$ e apoiaram o movimento incondicionalmente mesmo com as mortes que se registravam no seio da população. ${ }^{9}$

O segundo período é situado entre os meados de 1984 até o final de 1989, anos em que os

\footnotetext{
8 Apesar de isso não ser um motivo suficiente para anular a gênese externa e interna da criação da Renamo, inicialmente é evidente que tinha as bases e origem interna com ajuda externa assim como aconteceu com a própria Frelimo.

9 A formação da Renamo foi a comando de André Matsangaisse, ex-comandante e desertor da Frelimo.
} 
renamistas moçambicanos legitimaram seu poderio político e domínio total do movimento sob comando de Afonso Dhlakama, e sem ajuda da África do Sul nem da antiga Rodésia do Sul, a guerrilha desencadeia uma nova forma de expandir a guerra e ocupa todo o território nacional. Nessa nova fase, a guerra se tornou insustentável para o governo de Moçambique, porque começaram a existir bolsões de fome, epidemias e a economia entrou em colapso. É quando o governo começa a se preocupar em como conseguir conversações com a liderança da guerrilha.

Aqui a guerra passou a ser chamada de guerra civil. Nessa época a Renamo recebia apoio total das populações das regiões centro e norte de Moçambique, onde se fazia sentir a sua identidade politica. As ideias divulgadas pela Renamo eram de consenso na população e também em prol da conservação das culturas, línguas locais e tradições étnicas tribais, os líderes tradicionais viram na Renamo a recuperação do seu poder tradicional. Isso revelou o compromisso que o movimento tinha com a identidade moçambicana e construção de Estado inclusivo e moderno, contrariando o projeto de homem novo.

Geffray (1991) dá ênfase à alienação do campesinato de Moçambique pela implementação da Frelimo de aldeias comunais, operação produção e marginalização das autoridades tradicionais, com o foco principal para a Renamo ter controle da zona rural. Robinson (2006, p. 55) desvaloriza a ideia de Geffray, afirmando que as reversões dessas politicas não eram claramente reais, era apenas uma tática da Renamo para obter apoio local, nunca foram claramente articuladas como objetivos da organização, exceto talvez obliquamente sob os auspícios dos apelos à iniciativa privada e à extinção do comunismo. Mas, na verdade, a Renamo soube capitalizar essa política e serviu de isca para ter muitos apoios e fortalecer seu capital militar.

Esse periodo ficou essencialmente marcado por dois aspectos. Primeiro, a transformação do movimento desestabilizador patrocinado por estrangeiros a um movimento armado autossustentável. Em nivel ideológico/político funda-se uma Renamo com o programa político que no quadro da Guerra Fria reclama democracia multipartidária como leitmotiv da sua luta. Também é nesse periodo que se intensificou a guerra, depois de as forças armadas da África do Sul terem feito os últimos abastecimentos em material bélico para a Renamo.

A guerra alastra-se em todo o território nacional, a Renamo chega a controlar dois terços do pais e o movimento atingiu "20 mil guerrilheiros, (OLIVEIRA, 2006), num pais que tinha uma população de cerca de cinco milhões e atingiu o recorde africano em números de guerrilheiros em relação aos outros rebeldes africanos. Isso preocupou a Frelimo e a comunidade internacional e começou a fomentar pressão para pautar pelo diálogo para chegar ao fim da guerra e também alocar o regime político que o movimento propunha.

A morte de Samora Machel, no dia 19 de outubro de 1986, fez renascer a esperança do diálogo com o governo de Joaquim Alberto Chissano, porque, para Samora Machel, "a guerra se ganhava na base de combate e não pelo diálogo, o diálogo é aceitar que os inimigos da pátria têm razão ou venceram", ${ }^{10}$ o papel das igrejas na busca da paz consolida-se e os primeiros contatos para a paz são encetados, primeiro com a África do Sul e segundo por intermédio dos religiosos, governo Queniano, Tswana e Malawiano.

O terceiro e último periodo estendese entre o final de 1989 e outubro de 1992 , também reconhecido como guerra civil, mas com outra dinâmica diplomática. Nessa época a intensificação das ideias da busca da paz estendeu-se até a aprovação da segunda Constituição de 1990 e uma transição imediata do socialismo para o capitalismo, que surge em resposta à exigência da Renamo. ${ }^{11}$

Todas essas articulações feitas nesse periodo eram para construir um governo moderno que poderia responder às diversidades cultural e

10 TORELLY, M. Almanaque para 1949: primeiro semestre. Ed. fac-sim. São Paulo: Studioma: Arquivo do Estado, 1991.

11 Onde aparecia que o objetivo da Resistência Nacional de Moçambique é a democratização, a liberalização e criação de condições de progresso generalizado na República de Moçambique. 
étnica de Moçambique, visto que Moçambique tem mais de 10 grupos étnicos, 60 tribos, de Ruvuma ao Maputo e do Zumbo ao oceano Índico.

Paredes (2014) nos dá a entender que é correto afirmar a existência de múltiplas identidades étnicas no espaço que durante o periodo colonial português foi sendo chamado de Moçambique. Contudo, a vinculação de grupos étnico-culturais do período pré-colonial com o espaço político-territorial pós-colonial parece ser um trajeto com muitas fragilidades além de escamotear certa mobilização romântica e historicista do tempo histórico.

A Renamo "é um movimento ou partido que é um resultado da legitimação dos conflitos étnicos que o estado moçambicano, como a fonte da unidade nacional e epicentro da construção de um Moçambique novo e inclusivo" (ROESCH, 1989, p. 34). Para MERCIER (1961, p. 65.), uma etnia é um grupo fechado, descendendo de um mesmo antepassado ou, mais geralmente, tendo a mesma origem, possuindo uma cultura homogênea e falando uma lingua comum. Por seu lado, HONIGMANN (1964, p. 17) afirma que em geral, os antropólogos estão de acordo sobre os critérios através dos quais uma tribo (como sistema de organização social) pode ser descrita: um território comum, uma tradição de descendência comum, uma linguagem comum, uma cultura comum e um nome comum.

O discurso étnico não foi único a ser combatido também $O$ tribalismo seria a instrumentalização ou a manipulação das identidades étnicas com vista a tirar certos benefícios. Mas o tribalismo não pode ser visto apenas do lado negativo. Como afirma Christian Coulon (1997, p. 50), ele pode também constituir o veículo de reivindicações populares e, frequentemente, provocar paixões coletivas. No seu texto intitulado: o tribalismo da Frelimo, ilustrado pelo seu presidente, Eduardo Mondlane, que se tinha rodeado apenas por pessoas do Sul, tinha criado discórdia e divisões no seio dos moçambicanos.

A falta de consideração dessa realidade histórica e cultural faz com que os avanços econômicos, políticos e tecnológicos não ocorram, e Moçambique classifique-se como um dos países mais pobres da região. Já que no sistema do partido único de Moçambique, para ter emprego na função pública e ONGs, deve ser membro ou simpatizante do partido. Se prestarmos atenção, teremos a noção de que no governo de transição não se prestava qualquer apoio aos moçambicanos não filiados e alinhados ao partido e à política.

O Departamento de Estado tem relações diplomáticas formais com Moçambique e não ofereceu nenhum apoio, nem reconhecimento à Renamo de Dhlakama. De forma sistemática e firme, recusou ter quaisquer negócios com a Renamo, fazendo-se eco de Chissano ao denominar as forças da oposição de bandidos, as forças de resistência da Renamo, porém, são consideradas "bandidos" e muitos desejariam que elas fossem eliminadas para sempre. A Renamo não quer ou necessita de auxilio, mas gostaria de um ambiente equilibrado, quer da imprensa, quer a nivel diplomático (CAHEN, 1985).

A Renamo tem o seu projeto político que dá respeito à identidade étnica e cultural, ao contrário da $1 .^{\text {a }}$ República de Moçambique que negava tudo o que diz respeito à cultura de Moçambique, adotando a política de homem novo. Para além do homem novo, a Renamo estava contra a primeira Constituição que fazia confundir a história da Frelimo como a história de Moçambique e o sustento de existência de um e único partido.

A primeira República era uma ditadura Frelimista e militar, na qual o poder político era absolutamente do partido e dos dirigentes do Comitê Central. Todas as vontades do povo não tinham espaço, a vontade do partido é que devia coincidir com a do povo. Não havia a diferença entre partido e governo, algo que se estendeu até na segunda República apesar de não constar mais na Constituição. Como podemos ver no artigo $3 .^{\circ}$ da antiga Constituição (1975):

\footnotetext{
A República Popular de Moçambique é orientada pela linha política definida pela Frelimo, que é a força dirigente do Estado e da Sociedade. A Frelimo traça a orientação política básica do Estado e dirige e supervisa a ação dos órgãos estatais a fim de assegurar a conformidade da política do Estado com os interesses do povo Moçambique (MOÇAMBIQUE, 1975).
} 
Pode-se verificar nessa Constituição que não reinava o socialismo almejado por alguns lideres nacionalistas africanos durante as cimeiras da OUA, Julius Nyerere e Kwame Nkrumah, cuja ideia era de construir estados africanos socialistas com respeito à cultura, às etnias e às tribos. Essa ideia tinha como propósito elaborar constituições que respeitavam as diversidades culturais, éticas e tribais, aderindo, nesse caso, ao sistema federal socialista, recorrendo às políticas dos antigos impérios africanos. ${ }^{12}$ Mas para Moçambique o socialismo implementado foi o do sistema maoísta (chinês) misturado com o soviético e o cubano, e a ideia de identidade cultural étnica foi negada pelo governo. Isso resultou na formação de um governo totalitário e ditatorial no qual não havia espaço para qualquer cidadão dar sua opinião sobre a governabilidade do país.

Para fazer face a sua política, "o presidente Samora Machel funda os campos de reeducação na província de Niassa (M'telela) Gorongosa para onde eram levados seus críticos e opositores para serem presos e fuzilados e fortificar a sua política da ditatura" (CAHEN; MENDONÇA, 1994, p. 78). Cientes desse projeto político, alguns moçambicanos resolveram não aderir e optaram por fazer uma guerrilha para lutar contra o regime; nesse o rosto mais sonante é de André Matsangaissa, o primeiro comandante da guerrilha.

\section{Considerações finais}

Como nota final importa referir que muitos autores continuaram com os seus raciocinios asseverando que o movimento nasce também do descontentamento de uma parte substancial da população rural, sobretudo, do centro-norte do país, em relação às políticas socialistas da Frelimo e ao seu modo de execução. Jaime Nogueira Pinto anula completamente a tese de que a Renamo era simplesmente marionete dos interesses estrangeiro, coloca também o debate ao nível interno da Frelimo e socorre-se ao apoio incondicional que a Renamo teve com a população das regiões acima citadas.

Christian Geffray, no seu livro A Causa das Armas, Antropologia da Guerra Contemporânea em Moçambique, retoma o discurso mais enfatizado pelos cientistas políticos de que: Moçambique era uma base estratégica para a guerrilha dos nacionalistas da ZANU na Rodésia. Pouco depois da independência começavam a chegar a Maputo os primeiros cooperantes dos países socialistas - médicos, engenheiros da indústria açucareira e do algodão, professores, todos civis, mas soviéticos, cubanos, alemães de leste, romenos, búlgaros, coreanos... e, por último, os dirigentes moçambicanos impediam aos homens de negócios e industriais: rodesianos o acesso ao mar pela cidade da Beira na província de Sofala. Essa passagem mostra que foi nesse contexto que os rodesianos criaram o Mozambique National Resistance (MNR). Esta última parte visa contrabalançar a ideia principal da tese.

Nesta nota, importa referir que os homens referenciados por Dias, são considerados por André Matsangaissa como aliados principais para aquisição de material bélico e outras logísticas. Para além de ser suporte logístico também foram suporte para formar o que depois viriam a perder o sentido real do movimento.

Dias esconde a ideia de que os moçambicanos da Renamo rapidamente depois de terem material e treinamento suficientes desviaramse dos objetivos que tínham traçado, que era de criar apenas uma agitação. André e o seu grupo arrastaram o movimento para os seus objetivos. RENAMO: Terrorism in Mozambique é o livro de Vines que, de uma forma indiscutivel, podemos considerar como o mais abrangente já escrito sobre a Renamo. No livro, o autor examina a história da criação de grupos, a sua rede internacional de contatos, a sua estrutura interna, as suas táticas, os seus grupos dissidentes e as suas relações com a população de Moçambique.

Vines enfatizou que, enquanto a Renamo não era uma marionete da África do Sul e tinha algum

12 Os impérios africanos estavam estruturados de forma federal, na qual havia o império máximo e estados vassalos chamados de reinos, dirigindo de uma forma étnica e tribal. Ao império máximo, os pequenos reinos pagavam tributos e garantia a área de segurança (militares) e alimentação ao império. 
apoio indígena, também carecia de uma ideologia clara e que operava, em grande parte, por coerção

Stephen fecha esse debate afirmando que foi dito frequentemente que as origens da Resistência Nacional Moçambicana, mais conhecida pela sigla portuguesa Renamo, são bem conhecidas. Mas como muitos aspectos que cercam a Renamo, e até mesmo a própria guerra, os fatos tornaram-se obscurecidos por mitos, meias-verdades e distorções claras dos eventos históricos reais. Tanto os apoiantes da Renamo como os seus detratores procuraram criar uma imagem do movimento insurgente que refletisse as suas próprias agendas específicas.

\section{Referências}

CAHEN, Michel. État et pouvoir populaire au Mozambique. Politique Africaine. Paris, Karthala, 1985

CAHEN, Michel; MENDONÇA, Fátima. Resistência Nacional Moçambicana. Geschichte, 1994.

CONSTITUIÇÃO da República Popular de Moçambique de 20 de junho de 1975. Impressa Nacional de Moçambique, 1975.

COULON, Christian. Les dynamiques de l'ethnicité en Afrique noire. In: BIRNBAUM, Pierre (dir.). Sociologie desnationalismes. Paris: PUF, 1997. (Coll. "Sociologies").

CRUZ, D. Para onde vai angola: a selvajaria apocaliptica onde toda perversidade é real. Luanda, Angola: edições Mulemba, 2008. Vol. I.

ESTATUTOS DA RENAMO. Renamo, 1989.

FLORÊNCIO, Fernando. Cristian Geffray e a Antropologia da Guerra. Ainda a propósito de lá cause dês armes au Mozambique Etnográfica. Revista do Centro de Estudo em Antropologia, n. 2, v. VL, nov. 2002.

FOUCAULT, Michel. O corpo utópico, as heterotopias. São Paulo: n-1 Edições, 2013.

GEFFRAY, Cristian. A causa das armas, antropologia da guerra contemporânea em Moçambique. 1991.

HONIGMANN, John. "Tribe", A dictionary of the social sciences. Glencoe, Free press, 1964.

JORNAL LUSA DA RTP em o5 junho, 2015, 10:50.

MERCIER, Paul. Remarques sur la signification du "tribalisme actuel" en Afrique noire. Cahiers internationaux de sociologie, Paris, PUF, XXI, jul.-dez., 1961

MILL, John Stuart. Considerações sobre o governo representativo. Brasilia: Editora Universidade de Brasilia, 1981

MOIANE, José. Memórias de um Guerrilheiro. Maputo: King Ngungunhane Institute, 2009.
MSABAHA, Ibrahim S. R.; SHAW, Timothy M. Confrontation and liberation in southern Africa: regional directions after the Nkomati Accord. Westview Press, Boulder, Colorado, 1987.

NGOENHA, S. Elias. Filosofia africana: das independências às liberdades. Maputo: Ed. Paulistas, 1994.

OLIVEIRA P. Renamo: Uma descida ao coração das trevas. Lisboa: Europress, 2006.

PACHINUAPA, R.; LIPHOLA, M.; Tiago, P. Moçambique: 40 anos de independência e soberania. Maputo: Nachingwea Editores, 2015

PAREDES, Marçal de Menezes. A construção da identidade nacional moçambicana no pós- independência: sua complexidade e alguns problemas de pesquisa. Anos 90, Porto Alegre, v. 21, n. 40, 2014. https://doi.org/10.22456/1983-201X.46176

PINTO, Jaime Nogueira. Jogos dos africanos. Lisboa, 1994.

ROESCH O. Is Renamo a Popular Movement in Mozambique? Southern African Review of Books, dez. 1989.

ROBINSON, David Alexander. Curse on the land: a history of the Mozambican civil war. 2006.

SARTORI, G. Parties and Party Systems: A framework for Analysis. Cambridge: Cambridge University Press, 1976.

STV. Entrevista ao Afonso Dlhakama como presidente da RENAMO, 2014.

TORELLY, M. Almanaque para 1949: primeiro semestre. Ed. fac-sim. São Paulo: Studioma: Arquivo do Estado, 1991.

VINES, Alex. No Democracy Without Money: The Road to Peace in Mozambique 1982-1992. Catholic Institute for International Relations, 1994.

VINES, Alex. Renamo: From Terrorism to Democracy in Mozambique? London: James Currey, 1996.

\section{Celestino Taperero Fernando}

Doutorando em História pela Pontifícia Universidade Católica do Rio Grande do Sul (PUCRS, Porto Alegre, RS, Brasil). Bolsista do CNPq.

\section{Endereço para correspondência}

Celestino Taperero Fernando

Pontificia Universidade Católica do Rio Grande do Sul Av. Ipiranga, 6681, Prédio 8

Partenon, 90619-900

Porto Alegre, RS, Brasil 